\title{
State-sponsored dental terrorism?
}

\author{
M. Kelleher ${ }^{1}$
}

\section{In brief}

This opinion article suggests that the UK government's NHS contractual manipulations combined with fear of the GDC processes have had the perverse effects of terrifying many dental professionals while still failing to deliver effective and compassionate dental care for many patients.
It highlights some of the flaws and problems in the NHS and regulatory systems which are largely responsible for demoralising many dental professionals, and points out how this may have resulted in many patients not receiving the appropriately skilled dental care that is so badly needed to help them.
This opinion piece traces the effects of UK governments' historic and present bullying, which, the article asserts, has often resulted in unfortunate and perverse outcomes for many patients and dentists in the UK.

Has the state's manipulation of the NHS dental contract systems deliberately, or accidentally, had corrupting effects on the behaviours of some members of the dental profession? If the answer is 'possibly' or 'probably', then obvious questions that follow include, 'was this done deliberately' and if so, 'why'? Could this have been done for largely altruistic reasons, or was it done to achieve government control for minimum cost? Might this have been undertaken for political, financial or ideological reasons - regardless of any adverse longer term consequences for some patients or for some dental professionals? Might it have been done to take greater control of the dental profession on the grounds that all professions are a conspiracy against the laity, as the mildly paranoid George Bernard Shaw once alleged? Is it possible that some of this manipulation might have been done to help to disempower yet another profession, allegedly to 'modernise it', but perhaps to enslave it for its own reasons? Was this just another example of some statist politicians wanting to interfere in all aspects of UK society, regardless of their lack of specific understanding, or any proven expertise, in many areas? Could the state's manipulation of contracts and processes be regarded as an abuse of power by a virtual monopoly, which has been used to control a largely altruistic profession by imposing corrupting NHS dental contract systems with the most recent one involving 'units of dental activity' (UDAs)? Perhaps it was really about some politicians wanting ever more power, control or money their usual drivers - with the dental and medical professions accidentally becoming casualties?

\section{Deals with society}

In any democratic society fairly elected politicians have got an acknowledged shortish-term deal with society while the traditional professions have got a much longer-term deal. Those are not the same deals. The latter all involve considerable trust and recognition of the long education and certified training requirements to get in to them. However, inherent in these deals are also ethical and other responsibilities which involve credibility, reliability, experience and intimacy. What reduces trust quickly is the

${ }^{1}$ Specialist in Restorative Dentistry and Prosthodontics, Bromley, Kent BR2 9EB ${ }^{*}$ Correspondence to: Martin Kelleher Email: info@martinkelleher.co.uk

Refereed Paper. Accepted 16 October 2017 DOI: 10.1038/sj.bdj.2017.983 real or perceived self-interest of the other party predominating in any relationship.

Politicians, of different hues, have been allowed to take the unchallenged 'assumed close' that the state and its politicians really do know best about all the complexities of all healthcare, including dental healthcare. This outcome has been achieved with the help of various government spin doctors who are skilled in the use of new and old media. One recent change is that while some political messages about the various problems and issues in dentistry get sent out in the traditional media, sometimes different 'versions of the truth' also get pinged on out in to the digital moronosphere where they get consumed by those addicted to little doses of dopamine delivered to them by constantly checking Twitter, Facebook or Instagram, where anyone can appear to be an expert.

\section{Statist re-disorganisation?}

Some of us oldies have been through five NHS re-disorganisations and none of them seem to have made dentistry easier or more effective to deliver, or have been proven to deliver reliably better outcomes for patients or for dentists. Instead, multiple regulators have been commandeered as agents of the state and have grabbed, or been granted, so much power that they now intrude menacingly into many dental professionals' lives. The slide into UK governmental control of the dental profession was slow, quiet and Machiavellian. Nominal self-regulation of the dental profession was eroded gradually by means of the state influencing regulators, bureaucrats, or lawyers to interpret various labyrinthine regulations to the state's advantage.

UK agencies such as the supposedly fair and independent GDC, but including the 
increasingly politically-controlled NHS commissioners, the HSE and the CQC have had unfortunate effects on many dentists' clinical practices. The outcomes have not always been benign. Some recent events have had devastating effects on some dentists and their team's morale and behaviours, with these pressures increasingly becoming burdensome, bullying and terrifying for some. A possibly unintended, but understandable, perception of that terror is that many dental professionals now think that their first duty of care in dealing with difficult, sometimes urgent, clinical problems presenting in patients is to stay within often mutually conflicting guidelines or 'regulations'.

\section{The 'ménage a trois' in dentistry}

There is now a sort of tacitly accepted 'ménage a trois' going on in UK dentistry involving the patient, the dental team and one of the regulators so that many dentists now are trying to serve at least three 'governors. These are the 'patient's best interests' while simultaneously trying to appease the often conflictingly expressed, or implied, interests of different regulators. To this complex mix one ought to add in various financial pressures including serious debt, various organisational and ownership changes, as well as complicating social shifts and different demand factors.

On one side of this complicated mess, most dentists and their teams start off trying to 'do the right thing' for each patient, but increasingly many are being forced to think (consciously or subconsciously) about how to stay out of potential trouble with the questionably proportionate GDC, the much revered CQC and/or the box ticking HSE. To that trio one can add some new acronym for a commissioner of some dental services. It often seems that long-term decisions about better dental healthcare have been based on the whim of some spotty management consultant, or some half-baked civil serpent (sic). Whenever they set out to re- disorganise UK dental healthcare once again it appears that they justify their new policies on selective interpretation of dubious statistics, or to base them on the findings of some questionably informed or balanced focus group or committee.

\section{Lies, damned lies and statistics}

One way the government is economical with the truth is by quoting the reduction in total edentulism as proof that dental health is improving in the UK. The state claims that this surrogate marker is reasonable justification for not needing to increase dental investment, but in choosing this simplistic and dubious measurement it falls victim to 'McNamara's Fallacy', which is 'To make important, things one can measure, rather than measuring important things'.

The current dental problems in the UK are way, way more complicated than shown by an easily measured reduction in total edentulism. For instance, an increasingly ageing population have much more complex medical, dental and social problems, higher dental health aspirations and increasingly greater need for sophisticated dentistry. It is understandable that some older patients feel that they have been conned out of their dues after having paid taxes and National Insurance all their lives, which they did based on the assurances that the UK state would come to their aid in their hour of dental need. Rather than stating the financial reality, which is that the state is now skint, and has other priorities than funding dentistry for them, politicians prefer instead to transfer all the blame for patients' difficulties in getting their appropriate dental care on to the dental profession. They do this by subtly manipulating contracts and fees so that it is often not feasible to provide the desirable preventive, or time-consuming routine, or sometimes sophisticated dentistry for the state determined paltry fees involved. It is a sad fact that the ageing heavy metal brigade have been placed in their current predicaments by previous governments' fee-per-item of service contracts and then effectively abandoned under the present UDA system. Many of these heavy-metal-style restorations were placed with the state's agents giving 'prior approval' and were overseen by the DPB and the Stasi-like RDOs checking that they had been delivered in pursuit of their mystical 'dental fitness.' This yawning gap between many patients' expectations and the NHS dental reality grows greater with each passing year and is the source of much anger and frustration. Cunningly, the state chooses to hide behind the illusion that extensive remedial treatments, like multiple endodontic treatments, are still theoretically possible - but only if the NHS general dental practitioner wishes to accept monumental financial losses and incur other complaint and legal risks in doing so.

\section{Perverse outcomes?}

Subtle but inexorable pressures force many dental professionals to adopt a 'just doing my job in this system' approach. However, for many dentists' teams, taking this semiinstitutionalised position can create serious ethical conflicts with their more important and overriding duty of care which is to do 'the best thing' for that patient at that time and to try to look after that patient's long-term best interests for the right reasons. ${ }^{1}$ That understandable selfpreservation approach can then become normalised, partly due to the terror now being felt by many dental teams. These perceptions are based on stories of the consequences of some colleagues running afoul of some menacing 'powers' or 'controllers'. This fear can be based on real reports and various insinuations or veiled threats from some allegedly independent regulator. In some cases this can result in an understandable default position which is not to get caught in the maze of questionably legal 'guidelines', or the web of diktats that increasingly now rule, if not actually ruin, the lives of many UK dental professionals.

What is to be done about this state sponsored dental terrorism? Can it, or ought it to be challenged? If so, how can this be done effectively and when?

Many ethical dentists now feel threatened and spend much of their time shaking their heads in disbelief at the lack of common sense, or proportionality, as demonstrated in various reported cases. It is important that bad, mad (or both) registrants are identified early, sanctioned and/or removed from the register when the problems involved are serious, but that this is done only after fair and due processes have been followed. However, as a consequence of this fear of possible complaints some dental procedures that many older dentists would regard as routine, such as moderately difficult extractions or molar endodontics, are sometimes avoided or referred to hospitals, by these understandably now risk-averse dentists. This is sometimes as a result of a multiply flawed UDA system, but that can also be combined with a nagging fear that 'something might go wrong.' If that happens they might then get a complaint by a less-thantotally-satisfied 'entitled consumer' and then get caught in the GDC's draconian complaint processes.

If a complaint is received, then some GDC committees' 'holier than thou' views are sometimes supported by a supposed 'expert' from a very narrow subspecialist field of dentistry, or by some very occasionally wet fingered academic drafted in from some ivory tower. These 'experts' rarely, if ever, operate in the real world of current NHS general practice and are usually seeing the problems of others with 20:20 hindsight and through their well-polished 'retrospectoscopes'. If, as is 
suspected, some derive much of their income from being 'GDC experts', then you can't get much narrower, possibly biased, expertise than that. It seems that some registrant members of some 'Fitness to Practise' panels spend more time sitting on these committees than they now spend doing real live dentistry.

Given the finger wagging approaches and the power of the GDC it is not particularly surprising that some nervous, inexperienced - or now even experienced dentists - can legitimately claim that in refusing to get involved with some patients' problems and referring the problem on, they are merely obeying the GDC's stipulations about acting within one's competence.

One quick question, please? How does one get competent and maintain competence? By practising over and over again; it is no coincidence that we are described as 'practising. The majority of sensible, experienced people accept that there are learning curves and often lots of repetition involved in getting better at various clinical procedures. Needless to say, lessons have to be learnt quickly from encountering various clinical problems and the relevant skills improved as a consequence. One needs to be alert in constantly recognising deficiencies and strive not to repeat errors or to continue to make clinical mistakes that might damage patients. On the other hand, one should not be unnecessarily terrified into not trying to do one's best to help with a patient's problems for fear of a hugely disproportionate reaction if there are occasionally suboptimal results which do not do serious damage. The perverse but predictable outcomes of this perceived terror include hospital departments being flooded by inappropriate referrals and society getting a worse service from a less skilled and/or a demotivated workforce.

Some legitimate questions need to be asked such as 'can the GDC prove, beyond reasonable doubt, that it is completely independent of government interference and a fit for purpose organisation? Can it prove that it acts fairly and proportionately at all times? Can it prove that it is composed largely of experienced, objective, trained professionals who, as a direct result of their work actually do deliver measurably better outcomes for most dental patients? If so - which some dentists doubt - can it be shown clearly that they are doing so in direct proportion to their legal and other costs?' Clinical assessors, who are neither GDC Council nor Committee members and whose role it is to check decisions being made by GDC case workers, could and should have been made independent of the GDC but were instead made GDC employees - which many consider to have been as mistake as their neutrality is possibly undermined by that employed status.

Dentistry is a mutual trust profession. Can the GDC really justify effectively destroying patients' trust in dental professionals, but not replacing that trust in any measurable way?

\section{How did we get into this mess?}

A very good question and it probably happened because of the "law of unintended consequences.' ${ }^{4}$ The oft quoted sacred cow mantra that 'the NHS is the envy of the world because it is free at the point of delivery and accessible to all based on need' has not been true in dentistry for over forty years as patient charges and different payment systems have been introduced. Yet, for some reason, nobody openly challenges this blatant lie or draws enough attention to government's constant meddling and financial tinkering to try to control NHS dentistry.

The state takes no responsibility for the consequences of imposing contracts on many dentists, even when there are serious consequences for many patients' long-term dental health, for example, in the failure to reward genuine preventive measures, or to encourage minimally destructive management of significant tooth surface loss. ${ }^{5}$ Dare one suggest that the GDC might be considered to be tacitly complicit in some of this, in so far that it makes no comment on the market manipulation by what is the dominant dental stakeholder in many parts of the country and insists that the standard of care should be the same regardless of whether it is provided under the NHS UDA system or via another system?

If the GDC was actually a robust defender of patients' long-term interests it would not be an unquestioning lapdog of the Department of Health (DoH). Instead, their people there should be stating openly to patients that it is impossible to provide high-quality technical dentistry consistently for minimal fees. Do they do this? Answers on a postcard, please. A more realistic and reasonable expectation would be a standard of outcome that is proportional to the time, resources and money actually (ie not theoretically) made available to achieve this - which is what happens in most other areas of life. Perhaps the government, or their pet regulator are rather too busy issuing various bits of supposed 'guidance' which is often couched in impenetrable 'doublespeak' in order to control dental teams.

\section{State-influenced fees}

Partially or completely edentulous patients in many areas of this country cannot get welldesigned or well-fitting cobalt chromium partial dentures, or satisfactory complete dentures. This is a particular problem under the terms and conditions of the NHS, where the fees paid to dentists for removable prostheses are derisory.

The better skilled laboratory technician's costs already greatly exceed the total amount payable to the NHS GDP who is therefore forced to compromise and supply a 'BSID' (British Standard Issue Denture). In relation to complete dentures, a BSID can mean poor retention or stability, due to inadequate extension or to occlusal problems of the dentures provided. In the case of partial dentures, a BSID means there is often little evidence of surveying being done first of all, or of proper guiding planes being prepared, or of other sensible mouth preparations being done in advance of the master impressions being taken. Sadly, the typical BSID acrylic partial dentures supplied often do not include wellfitting guiding planes, or appropriate rest/clasp assemblies to help to stabilise these dentures.

However, that said, that is the de facto average standard in the UK and therefore might well pass a Bolam Test. Whether it would pass a Bolitho Test (that is, would this actually withstand logical scrutiny by a judge) is more open to question. The GDC publishes 'standards' yet turns a blind eye to the very real financial difficulties and practical realities of many dentists in trying to achieve good clinical standards for patients, as though that is not part of the GDC remit.

It is a national scandal that the internationally agreed consensus standard for treating patients with edentulous mandibles to be routinely supplied with two implants to retain a lower denture is not being implemented routinely for these dentally disabled patients in the UK. ${ }^{6,7}$ Some units do their best with the very limited resources and within varying commissioning criteria but the overall provision of such treatment in the UK - the supposed envy of the world in healthcare - is very patchy indeed. This is in spite of copious evidence of a marked improvement in the quality of life of patients when the edentulous mandible is treated in this well-proven way. 


\section{History of government policies}

At the advent of the NHS in 1948 there was no fluoride in toothpaste, the consumption of sugar, when available, was very popular, smoking was widespread and oral hygiene techniques were primitive. Taken together these factors had resulted in gross dental diseases. One of Nye Bevan's main premises in establishing the NHS was that effective elimination of many diseases from the population would mean that thereafter healthcare costs would be cheaper for the state in the longer term. In the case of the gross caries and periodontal diseases then present, disease elimination was encouraged by means of multiple extractions and dentures with statedetermined fees derived entirely from general taxation. There were no patient payments. There were no air-rotors at that time, but there were forceps and elevators readily available along with dentists who were very skilled in how use them. The 1950-60s have been referred to as the 'blood and vulcanite' era as this was the material used prior to acrylic resin for dentures.

The point here is that efficient removal of various dental diseases - regardless of the traumatic human consequences - had become 'politically correct' as a readily understandable quick solution based on the 'greatest good for the greatest number' and this was philosophically accepted by the profession, aided greatly because it was reasonably well remunerated. As a consequence, the financial outcome as planned by Nye Bevin, was that there was minimal cost to the state in the patients' later life because there were no teeth left and complete denture technology was relatively cheap. In summary, the state at that time got what it wanted by manipulating the NHS remuneration system - the state sponsored dental terrorism of those days - with many dentists doing its bidding.

In mitigation, however, there was so much dental disease of such horrendous and dangerous severity that many people did benefit enormously from that policy, even if there were quite a few casualties with some having unnecessary extractions being undertaken for social demands, or for practical prosthetic convenience.

\section{The high speed drill}

In 1949, John Patrick Walsh invented the high speed drill in New Zealand. Borden developed this further in the USA and in 1957 produced the Borden Airotor. When this instrument was combined with burs of various sizes, shapes and with better dental materials it revolutionised dentistry. Now the decay could be accessed and removed quickly, classic cavities could be cut and teeth could be restored that previously would have been removed. However, the state's remuneration system fees had been based on slow drills and this 'disruptive technology' of that time resulted in dentists being able to do dentistry much more efficiently and therefore their incomes soared. In effect the dentists were now encouraged to save teeth rather than extract them. They did whatever dentistry they deemed was appropriate, based on a 'fee per item of service. Dentists sent their whole bills to the government who paid them out of general taxation, without any further fees being paid by the patient at the point of delivery of their treatment as all UK citizens were covered for this allegedly 'free' NHS dentistry.

UK government health policy then changed to try to limit patient demand by introducing patient charges, thereby making it no longer free at the point of delivery as Nye Bevan had promised. Initially, patients had to pay a one pound ( $£ 1)$ contribution. This rose to a thirty shillings ( $£ 1.50$ - but this was a $50 \%$ rise in those pre-inflationary times) and it was the maximum payable regardless of the amount of treatment required. Charges then rose to $£ 3.50$ and then $£ 10$ as the government tried to raise income as well as reduce demand further, but this was still a trifling amount by comparison with the cost of treatment which was still largely paid by the government.

Fillings, root fillings, crowns, bridges, dentures or extractions all had their separate fees, which were adjusted periodically, under what was termed the 'Statement of Dental Remuneration'. Many older dentists remember them, possibly some through rosetinted glasses, as being a series of 'swings and roundabouts. The dentist gained on some cases and lost on others, but overall the patients got treated reasonably well, dentists had reasonable freedom to do what the patient wanted/ needed and they were reasonably well paid for doing so. However, that system then was a bit of an open cheque book as far as the state was concerned, in that it did not explicitly control the overall state expenditure on dentistry.

Unfortunately, for the reputation of the dental profession generally, under that system some excessive treatments were probably undertaken by some dentists for philosophical reasons ('extension for prevention' was one common justification) or possibly to increase some less honourable dentists' incomes. Whatever the real reasons, some trust was lost in the dental profession. Reference Dental Officers (RDOs) regularly checked dentists' work and that they were fulfilling their NHS contracts in delivering all the treatment needed by any patient that they had accepted for treatment. For instance, free-end acrylic partial dentures were often made to comply with the NHS regulations. Many of these were never worn by the patients as they had no perceived benefits from wearing clasp-less loose dentures for their free-end saddles and many preferred a shortened dental arch, but partial dentures still had to be supplied to 'secure dental fitness' and thereby comply with the government's regulations.

\section{Government claims}

One favoured half-truth by government was, and is, to claim that they spend $£$ xyz millions on NHS dental services but they include quietly the patients' charges in that overall figure that they quote. Dentists, incidentally, have to account for all that patient charges money, which obviously requires extra staff to administer, unlike those nice NHS doctors who do not charge for their services. The oft-repeated nonsense, therefore, that NHS healthcare is free for all at the point of delivery, has not been true since the 1960s. The facts are that patient charges and various regulations have frequently had profound effects on dental treatment and prescription patterns.

\section{Dental problems in older people}

There are now increasingly numerous ageing 'heavy metal' patients surviving very many more years than the traditional 'three score years and ten'. Many of them are kept alive by multiple drugs which frequently cause xerostomia as an unwanted effect of their usage. Many older people now have complex restorations including crowns, bridges and various structurally compromised partly root-filled teeth. The ongoing requirements for care, experience, skills, time and technical support for these deserving patients are potentially huge. However, the state quietly worked out subtle contractual and bureaucratic ways of limiting the practical availability of many of these now technically possible treatments.

The dramatic fall in the number of dentists doing root fillings on molar teeth since the introduction of the UDA system bears witness to the consequences of interference in systems and fees altering treatment prescriptions or referral patterns. How exactly does 
the extraction of many teeth which could be root filled pragmatically and at least 'semi-preserved' with a decent well-sealed restoration, if there were fair NHS fees for doing so, actually benefit patients in the longer term?

Which dentist in his or her right mind would want to undertake technically difficult, time consuming, delicate molar endodontic procedures involving expensive equipment for financial peanuts - a paltry 3 UDAs - and in addition possibly be blamed some years later for an academically 'sub-optimal' (but functional) result, by some lawyer's tame specialist or some academic endodontist who actually now rarely, if ever, treats NHS patients in general dental practice? The average standard of endodontic treatment in the UK (and indeed elsewhere in the world) is actually very different to the supposed 'academic ideal' but that is the average standard (Bolam Test) against which general dentists ought to be judged. Just please have a wild guess at which standard the GDC often chooses to apply if there is any patient complaint?

On the other hand, if the GDC is actually aware of the practical effects that the UDA system has caused and has done nothing in practical terms to ensure such patients' best interests are really looked after, eg, by not challenging that multiply flawed state system, then surely that suggests some tacit collusion with government? Some neutral observers might mutter the term 'hypocritical'. If the folk at the GDC were being really honest they should know that it is impossible to provide the highest quality outcomes in dentistry consistently for derisory state controlled fees. Yet they persist with their assertions that the highest 'standards' of patient treatment can be miraculously achieved in this multiply flawed NHS system.

If they were properly informed and therefore more realistic about dentistry being an imperfect science, ${ }^{2}$ with treatments usually being done in imperfect patients, they should recognise that there is quite reasonable evidence that teeth survive with pragmatic, if academically suboptimal, treatment such as with a non-ideal root filling and a well-sealing restoration on top. ${ }^{3}$

\section{Pious platitudes and oxymorons}

To most experienced people the words 'cheap, quick, and high quality' when used all together in one sentence constitute a blatant oxymoron, which means a mutually paradoxical statement. Business people will tell you that you can get two out of these three things, but you cannot have them all in any deal. Yet this nonsense gets trotted out with monotonous frequency by politicians or others and gets challenged infrequently. In truth, rapid access to highquality and durability in dentistry comes at a commensurate cost. Some politicians, gullible patients and regulators, who really should know better, apparently think you can have all three. 'Two out of the three' is the rule and therefore you have to choose which 'two out of three' one wants in modern UK dental healthcare. This has been termed the 'iron triangle of healthcare' and involves juggling issues of access, cost and quality.

One version of this 'iron triangle' argues that out of the same finite financial resources for healthcare it is possible to get access and reasonable, but not necessarily great, outcomes for many people. Alternatively, one can have great, quickly treated, results for very many fewer people. Which is it to be? Is it time to stop lying to people that 'cheap, quick and highest quality' is possible out of the same limited healthcare resources?

\section{Efficiency and costs}

The furore about the GDC raising the annual retention fee (ARF) was based on their chosen management consultant advice that if the dentists, as their main funding source, just handed them a mere $60 \%$ plus increase they could then improve on their well-known inefficiencies and their Kafkaesque fitnessto-practise processes. What really hacked off a lot of dentists was not having to pay more as such, but having to pay more for what many perceived to be an unfair, inefficient, unrealistic, and occasionally vindictive organisation. Many dentists might well be quite happy to pay even more if it meant getting some efficient, fair, proportionate and realistically informed treatment from an organisation that used a bit of common sense and some sensitive discretion occasionally. For instance, the GDC might recognise sometime that actually dentists do not cause dental decay, or periodontal disease, or force people to smoke or to have genetic susceptibility to oral diseases.

The GDC moral position to continue to regulate dental professionals has been weakened recently in other ways. For instance their position on dental bleaching was farcical for many years. ${ }^{1}$ It never really managed to stop illegal dental bleaching effectively for example, in shopping malls by untrained 'beauticians'. If, however, dentists had allegations made against them of that sort of level of non-compliance about history taking, or their note keeping, or questionable cross infection control they would be off the register very quickly. Sorry, they would be off after an agonising wait for their case to be heard when the inquisitional GDC was good and ready to deal with it, having possibly ruined the dentist's reputation by publishing details on their website, sometimes based on some spurious complaint or on some, as yet, unproven allegations. Dentists have the same human rights to be treated as fairly as anyone else, mainly because, the last time I checked, most of them were humans before they became dentists.

\section{Unrealistic expectations?}

There are many reasons for patients' expectations increasing about what dentistry might be able to provide for them in a Utopian society. Sadly, we don't live in Utopia. Populist, if mindless, vacuous, or superficial television programmes such as 'Ten Years Younger' unleashed a tidal wave of sometimes narcissistic expectations in some patients, regardless of the inherent biologic costs of some of these quick, destructive or unpredictable approaches which were shown.

The state, for its part, has also been busy encouraging increased expectations in patients about their 'entitlements'. However, unfortunately they forgot to supply some honest balancing information about the UK treasury not agreeing to provide the commensurate financial resources to fund those hugely increased patient expectations.

Dental teams now have to keep even more copious, time consuming notes, just in case of any possible complaint in the future. However desirable this is, it often has to be done at the expense of the available time to do the actual treatment. The real dilemma is this: does the patient get the desirable communication and copious notes - but no actual treatment and a referral to someone else - or get treatment there and then to solve their problems? In purely practical terms they often cannot have both out of the same state limited fees. Which is the more desirable outcome of these often competing options and what is the justification for choosing one approach rather than the other?

\section{Patients or consumers?}

Dentists should be allowed and encouraged to look after the best long-term interests of patients and those altruistic and compassionate aims should be helped and not hindered by a less terrorising state or GDC. Dentists 
should not feel pressurised by an appointed GDC chairman who readily admitted in one address that he knew little about dentistry. That did not stop him opining that, in marketing terms, dentists should be doing 'whatever the consumer/customer wants'. Reducing the status of patients to being mere consumers of dental healthcare is facile, simplistic, demeaning and possibly dangerous for them and for dental professionals. There was not a single mention of compassion or of the role of professional judgment in that same address, as though these are rather tediously old fashioned or unimportant concepts.

I would challenge that simplistic model of treating any patient as merely a 'consumer'. However, if that consumer model is to be used, as advocated by GDC Chairman, Mr Moyes, then perhaps before the GDC, or the state, blames dentists for many of the problems about which these supposed 'consumers' complain, a few moments of reflection on some facts might be helpful for them.

1. Dentists do not cause tooth decay or periodontal disease

2. Most dental diseases are self -inflicted by 'consumers' due to their own sugar consumption frequency, ineffective cleaning and/or smoking. These are consumer habits

3. These risk factors are largely outside of the control of dentists or of other dental professionals. Dental professionals can advise but not force patients to control such dentally risky behaviours

4. Sadly, even if dental professionals do give appropriate advice, the evidence is that many patients do not pay much attention to, nor comply with advice about their consumption habits, for example, about smoking. ${ }^{8}$ In one smoking study, less than one third of patients would try to quit smoking if their dentist suggested it and fewer than $20 \%$ could even recall being given smoking cessation advice. Interestingly, many smokers still ignore the causal links between smoking and periodontal diseases as well as the widespread medical warnings about it causing different cancers and heart disease. ${ }^{9}$

They also manage to ignore the graphic warnings on the cigarette packets that smoking will kill them and yet some still blame dentists if their teeth get loose after many years of smoking and fall out or need to be removed. Is that not bizarre, illogical 'consumer' behaviour? How do they smoke? Do they stick the cigarettes up their bottoms? Some smokers and their lawyers, especially if the fees involved are considerable, do not seem to think that the patient could ever be at fault in causing their own problems. Unless the dentist's notes can prove that the patient was told specifically about smoking and gum rot in their particular case, many periodontal disease cases are difficult to defend and the costs are often enormous. The allegedly all-knowing politicians and the good folk at the $\mathrm{DoH}$ and the GDC might care to reflect on these salient facts before encouraging patient complaints and criticising dentists unfairly.

\section{The state and the GDC}

It appears to many observers that the GDC is now unquestioningly statist. In other words, they tacitly support a system in which the state should exert centralised control over dental and economic affairs, regardless of the many problems for patients and dental professionals that this now causes and has caused in the past.

What do the government and the GDC need to do to repair the damage and regain the trust of the dental profession? A good start might be to recognise the terrorising effect that they have had on many dental professionals. The GDC, in particular, needs to listen carefully to the many criticisms that have been made:

- They need to show some sort of insight into their failings and act fairly and proportionately in the future

- They need to be measured and proportionate in their assessment of what might be genuinely important issues of fitness to practice as opposed to what could be malicious intent by a patient who complains to them, for example, for mainly commercial dispute reasons, as a result of a personality clash, or for vindictive reasons

- They need to reflect on the old adage that 'there are three versions of the truth' (the patient's, the dentist's and the actual truth) rather than assuming that the patient is always right or reasonable

- They should not assume that the dentist is wrong, or unreasonable, until they know all the relevant facts and circumstances and can prove some serious wrongdoing

- Dentistry, like most surgery, is an imperfect art or science. ${ }^{2}$ Life is seldom perfect.
Dentists, patients and the GDC are not perfect either. Some common sense, mutual tolerance and sensible discretion should be allowed for that

- They should avoid ruining dentists' reputations by one-sided publicity of some unsubstantiated patient allegations, until fair and balanced due processes have been carried out

- They should become a more effective defender of patients' longer-term interests by questioning the government closely about the multiply flawed NHS systems in which many dentists have to work, rather than acquiescing in a supine way to various UK government departmental diktats.

Many state policies have now been shown to be seriously flawed in relationship to real and present dental problems, as demonstrated in the abject failure to deliver effective dental disease prevention strategies or effective treatment of gross caries in children.

Some of the state's contractual manipulations and half-truths have had catastrophic effects on the dental profession's behaviours, as well as terrorising many dental professionals.

Sadly, this perceived terror, whether real or imagined, has had many adverse, demoralising and unfortunate effects on some dental professionals, with the perverse outcome being that many patients cannot, or do not, receive the appropriate skilled dental care which is so badly needed to help them.

1. Kelleher M. The law is an ass: ethical and legal issues surrounding the bleaching of young patients' discoloured teeth. Faculty Dent J 2014; 5: 56-67.

2. Gawande A. Complications: A surgeons' notes on an imperfect science. London: Profile books, 2002.

3. Ray H A, Trope M. Periapical status of endodontically treated teeth in relation to technical quality of the root filling and the coronal restoration. Int Endod J 1995; 28: 12-18.

4. Merton R.K The unintended consequences of purposive social action. Am Sociol Rev 1936; 1: 894-904.

5. Kelleher M G D, Bomfim D, Austin R S. Biologically Based Restorative Management of Tooth Wear. Int J Dent 2012; Available at https://www.hindawi.com/journals/ ijd/2012/742509/ (accessed October 2017).

6. Feine J S, Carlsson G E, Awad M A et al. The McGill consensus statement on overdentures. Mandibular two implant overdentures as first choice standard of care for edentulous patients. Int I Oral Maxillofac Implants 2002; 7: 601-602.

7. Tomason J M, Feine J, Exley C et al. Mandibular two implant-supported overdentures as the first choice standard of care for edentulous patients -the York Consensus statement Br Dent.J 2009; 207: 185-186w.

8. Rickard -Bell G, Donnelly N, Ward J. What do Australian patients endorse and recall of smoking cessation advice by their dentists? Br Dent J 2003; 194: 159-164.

9. Lung ZH Kelleher MG Porter R et al. Poor awareness of the relationship between smoking and periodontal disease. Br Dent J 2005; 199: 731-737. 